\title{
Risk Factors for Early Weight Loss in Breastfed, Early Term and Term Newborns
}

\author{
Tijen Eren ( $\square$ tijen.eren@gmail.com ) \\ Koc Universitesi https://orcid.org/0000-0001-9650-3734 \\ Bahar Kural \\ Bakirkoy Dr Sadi Konuk Egitim ve Arastirma Hastanesi \\ Gulbin Gokcay \\ Istanbul Universitesi Istanbul Tip Fakultesi
}

\section{Research}

Keywords: Breastfeeding, newborn, early weight loss, risk factors

Posted Date: May 21st, 2020

DOI: https://doi.org/10.21203/rs.3.rs-27760/v1

License: (c) This work is licensed under a Creative Commons Attribution 4.0 International License. Read Full License 


\section{Abstract}

Background: Infants lose some of their birth weight before hospital discharge. This loss, which is accepted as "physiological" up to a certain level (5-7\%), is supplemented with food in early period for infants with over $7 \%$ of loss. While food supplementation does not have the benefits of mother's milk, it may cause low breastfeeding success in the long run. In newborns, the identification of risk factors affecting weight loss in a few days following birth will increase exclusive breastfeeding success. The aim of this study is to evaluate the risk factors that cause weight loss in newborns before hospital discharge.

Methods: Weight loss in infants born in a private trust hospital of Koc University American Hospital between 1 January 2011 and 31 December 2014 was evaluated. The hospital records of 3812 babies who completed the inclusion criteria were included in the study. The variables giving meaningful results in binary tables were evaluated with "Multivariate Logistic Regression".

Results: The increase in maternal age, Caesarean section birth, primiparity, female gender and being early term were statistically significant risk factors for early weight loss in newborns.

\section{Background}

As a global public health recommendation, the World Health Organization (WHO) and United Nations International Children's Fund (UNICEF) promote that infants be exclusively breastfed for the first 6 months after birth to achieve optimal growth, development and health (1). The first few days after the delivery, colostrum is produced and milk production increases. Weight loss following the first three days after birth is found to be around $5-7 \%$ for exclusively breastfed babies. Most clinicians judge weight loss to be concern when it exceeds 10\% of birth weight (2). When newborns lose weight over the desired limit, healthcare providers often get concerned that there is a problem with breastfeeding (3). Excessive weight loss after birth may cause maternal anxiety and reduced breastfeeding success alongside serious problems like hypernatremia and hyperbilirubinemia (4-6). Early onset breastfeeding problems may lead to supplementing with formula and falling short of exclusive breastfeeding target for the first six months of life (7).

It is important to identify the risk factors associated with infant weight loss during the first few days following birth common causes of which may be breastfeeding difficulties such as poor latch, ineffective suckling, nipple problems, mother-newborn separation. Newborn size, gestational age, metabolic and neurological disorders can cause excessive weight loss. Mother related risk factors for early weight loss in newborns are; breast surgery, mammary hypoplasia, retained placenta, hypothyroidism, Sheehan syndrome, polycystic ovarian syndrome, advanced maternal age and education $(2,8,9)$. Early term infants, born between 37 0/7 and 38 6/7 weeks of gestation, are also at higher risk compared to term infants, born between 39 0/7 and 41 6/7 weeks of gestation, for reduced breastfeeding initiation and duration (10).

The aim of this research was to identify significant risk factors for weight loss in a setting where caesarean section rate is high in breastfed, healthy early term and term newborns at early postnatal period. There are studies about early weight loss in newborns in Turkey $(11,12)$. Hamilcikan et at. investigated ethnicity and gender differences in 1428 newborns (11). In the other study, risk factors were evaluated only in a very small number $(n=34)$ of newborns (12). Our study is the first study that evaluates significant risk factors for weight loss in breastfed, healthy newborns in Turkey.

\section{Methods}

This retrospectively designed cohort study was based on the evaluation of postnatal hospital records of newborns that were delivered in a private trust hospital of Koc University in Turkey between 1 January 2011 and 31 December 2014. Changes in weight for all newborns were analysed.

A total of 3812 babies were included in the study. Babies who were non-breastfed, gestational age $<37$ weeks or $\geq 42$ weeks, presence of any metabolic or congenital disease, NICU admittance or/and APGAR score lower than 7, multiple births (twins, triplets) excluded from the study. Birth weight was not considered as an exclusion criterion. Flowchart of the study was given in Fig. 1. All mothers were offered 'breastfeeding education' between 30-36 weeks of pregnancy. Newborns were evaluated by a paediatrician immediately after birth. Skin to-skin contact and breastfeeding within one hour after delivery were early goals. A family medicine specialist who was also an International Board-Certified Lactation Consultant (IBCLC) evaluated all mother-infant pairs during hospital stay in order to reduce breastfeeding problems. Rooming in and exclusive breastfeeding were prioritised unless there was direct refusal from the mother or the presence of a medical complication of the mother or the baby. As soon as these conditions improved, newborns were placed to the breast. Routine weight measurements were performed until discharge, the first one being immediately in the delivery room and daily. Every day the babies were visited by a paediatrician and IBCLC. Length of stay varied by type of delivery. When weight loss amounts to $7 \%$ of the birth weight, measurements were taken every 12 hours or more frequently, re-evaluation of breastfeeding technique and additional breastfeeding consultancy was provided. Breastfeeding counselling interventions were given in Table 1. If latch was not successful manually expressed milk was given by cup feeding. In the study, those babies 
who were given expressed mother's own milk (MOM) was still assumed in exclusively breastfed baby. If MOM is inadequate and weight loss reaches $\geq 10 \%$ formula was initiated by paediatrician order.

Table 1

Breastfeeding counselling interventions

\begin{tabular}{|l|}
\hline Breastfeeding with under the supervision of IBCLC \\
\hline Breastfeeding in different positions \\
\hline Nipple shield use \\
\hline U-hold/C-hold with massaging of the breast during feeds \\
\hline Manual expression of mother's milk \\
\hline
\end{tabular}

Physiologic weight loss is defined as $5-7 \%$ loss of the birth weight (10). In this study, weight loss over $7 \%$ was identified as increased weight loss. Risk factors related to neonatal weight loss that were evaluated in the study listed at Table 2. Early term refers babies born between $37-$ 38 6/7 weeks of gestation (10).

Table 2

Risk factors evaluated in the study

\begin{tabular}{|l|}
\hline Maternal age \\
\hline Parity \\
\hline Gestational week \\
\hline Birth Weight \\
\hline Delivery type \\
\hline Anaesthesia method \\
\hline Conception method \\
\hline Infant gender \\
\hline Maternal hypothyroidism \\
\hline Maternal cosmetic breast surgery \\
\hline Maternal increased insulin resistance \\
\hline Maternal gestational diabetes mellitus \\
\hline
\end{tabular}

From maternal records, anaesthesia method during delivery (spinal or general anaesthesia), conception method (spontaneous or In Vitro Fertilisation -IVF) and the presence of cosmetic breast surgery were noted. Maternal gestational diabetes mellitus (GDM) is defined as any degree of glucose intolerance with onset during pregnancy. All mothers included in the study were screened for GDM during pregnancy with a laboratory-based screening test(s) using blood glucose levels. Maternal increased insulin resistance was calculated from fasting maternal plasma glucose and insulin concentrations obtained during pregnancy (13). Maternal hypothyroidism was detected by obtaining TSH levels with free thyroid hormone levels (14). In the study, maternal metabolic and hormonal diagnosis were based on pregnancy follow-up notes found in the maternal records.

Ethical and institutional approvals were obtained.

Number Cruncher Statistical System 2007 (NCSS Kaysville, UT, USA) was used for statistical analysis. In analysis descriptive statistical methods such as mean, standard deviation, median, frequency and ratio were used. Pearson Chi-Square test was employed for comparison of qualitative data. Multivariate data were assessed by Logistic Regression (Backward Stepwise) analysis. All results were evaluated in the $95 \%$ confidence interval, with $\mathrm{p}<0.05$ level of significance.

\section{Results}

Hospital records of 3812 healthy, term newborns were evaluated for this study. All these newborns were initially exclusively breastfed after delivery. Only $14.9 \%(n=565)$ of newborns supplemented by formula during hospital stay. The majority of mothers were over 30 years of age (79.5\%). Majority of the mothers were primiparous. Gravida, parity, gestational week and birth weight distributions were given at Table 3 . 
The male gender comprised $51.4 \%$ of the infants. The proportion of early term babies was slightly higher than half the population (51.5\%). Only $\% 0.9(n=36)$ babies was under $2500 \mathrm{~g}$ of birth weight. Babies were predominantly delivered via Caesarean section (CS) $(71.8 \%)$ and mainly under epidural anaesthesia (85.3\%). A total of 311 mothers conceived with IVF techniques. The majority of the mothers did not have any underlying medical conditions (85\%). Previous breast operation, hypothyroidism, insulin resistance and gestational diabetes mellitus were identified as underlying conditions (Table 2).

Mothers who deliver via vaginal birth had the mean of hospital stay was $46.02 \pm 16.2$ hours this figure was $71.35 \pm 7.57$ hours for mothers who deliver via CS. There is a statistically significant difference between the duration of hospital stay and mode of delivery $(p=0.001)$

Number of measurements, time intervals and weight changes of newborns were given at Table 5. Identified risk factors were compared between the group with a loss less than $7 \%$ and the second group equal or above $7 \%$. Overall, $58.3 \%(n=2224)$ of the newborns experienced weight loss that exceeded $7 \%$ of their birth weight. Weight loss $>7 \%$ of birth weight was mostly observed between $24-72$ hours after birth.

Table 5

Weight changes of newborns in the early postnatal period

\begin{tabular}{|c|c|c|c|c|c|c|}
\hline & & $\mathrm{n}$ & Min-Max & Mean & SD & Weight loss $>7 \% n(\%)$ \\
\hline \multirow[t]{5}{*}{ Weight (gr) } & Birth weight & 3812 & $2050-5190$ & 3378,17 & 398,86 & - \\
\hline & $0-24$ hours & 3784 & 1995-4990 & 3248,88 & 388,59 & 19 (52.8\%) \\
\hline & 24-48 hours & 3521 & $1920-4780$ & 3146,89 & 374,17 & $321(55.0 \%)$ \\
\hline & $48-72$ hours & 2738 & $1890-4660$ & 3129,76 & 378,12 & $1724(58.5 \%)$ \\
\hline & $\geq 73$ hours & 259 & $2090-4555$ & 3136,54 & 408,34 & $160(65.0 \%)$ \\
\hline \multirow[t]{4}{*}{ Weight loss (\%) } & $0-24$ hours & 3784 & $0-10,29$ & 3,86 & 1,76 & $124(3.3 \%)$ \\
\hline & 24-48 hours & 3521 & $0-13,45$ & 6,92 & 1,70 & $1791(47.0 \%)$ \\
\hline & $48-72$ hours & 2738 & $0,27-13,89$ & 7,57 & 2,13 & $1704(44.7 \%)$ \\
\hline & $\geq 73$ hours & 259 & $-1,18-12,33$ & 6,91 & 2,54 & 139 (3.6\%) \\
\hline
\end{tabular}

The rate of exclusively breastfed newborns during hospital stay was $85.1 \%$. Only $14.9 \%$ of newborns supplemented with formula alongside breastfeeding.

When analysing the risk factors, the first set of risk factors that were statistically significant in univariate analysis for early weight loss were; maternal age, parity, type of anaesthesia, in-vitro conception, gestational age by week, Cesarean section and gender (Table 4).

Table 3

Characteristics of Mothers and Newborns ( $n=3812)$

\begin{tabular}{|lll|}
\hline & Min-Max & Mean \pm SD \\
\hline Maternal age & $19-52$ & $33.83 \pm 4,09$ \\
\hline Gravida & $1-9$ & $1.93 \pm 1,08$ \\
\hline Parity & $1-5$ & $1.44 \pm 0,60$ \\
\hline Gestation week & $37-41,29$ & $38.90 \pm 0,84$ \\
\hline Birth weight & $2050-5190$ & $3378.17 \pm 398.86$ \\
\hline
\end{tabular}


Table 4

Evaluated risk factors of Mothers and Newborns $(n=3812)$

\begin{tabular}{|c|c|c|c|c|c|}
\hline & & $\mathbf{n}$ & $\%$ & Weight loss > 7\% n(\%) & $p$ \\
\hline \multirow[t]{2}{*}{ Gender } & Boy & 1958 & 51.4 & $1093(55.8 \%)$ & \multirow[t]{2}{*}{$0.001^{*}$} \\
\hline & Girl & 1854 & 48.6 & $1131(61.0 \%)$ & \\
\hline \multirow[t]{4}{*}{ Maternal Age } & $19-30$ & 780 & 20.5 & $399(51.2)$ & \multirow[t]{4}{*}{$0.001^{*}$} \\
\hline & $31-35$ & 1767 & 46.4 & $1004(56.8)$ & \\
\hline & $36-40$ & 1069 & 28.0 & $684(64)$ & \\
\hline & $>40$ & 196 & 5.1 & $137(66.9)$ & \\
\hline \multirow[t]{2}{*}{ Gestational Week Distribution } & Early Term (37-38w) & 1962 & 51.5 & $1266(64.5)$ & \multirow[t]{2}{*}{$0.001 *$} \\
\hline & Term $(>39 w)$ & 1850 & 48.5 & $958(51.8)$ & \\
\hline \multirow[t]{2}{*}{ Parity } & Primipara & 2338 & 61.3 & $1430(61.2)$ & \multirow[t]{2}{*}{$0.001 *$} \\
\hline & Multipara & 1474 & 38.7 & $794(53.9)$ & \\
\hline \multirow[t]{4}{*}{ Birth Weight Distribution (g) } & $2050-2500$ & 36 & 0.9 & $19(52.8 \%)$ & \multirow[t]{4}{*}{0.051} \\
\hline & 2501-2999 & 584 & 15.3 & $321(55.0 \%)$ & \\
\hline & $3000-3999$ & 2946 & 77.3 & $1724(58.5 \%)$ & \\
\hline & $>=4000$ & 246 & 6.5 & $160(65.0 \%)$ & \\
\hline \multirow[t]{2}{*}{ Delivery Mode } & Cesarean & 2736 & 71.8 & 1961(71.8) & \multirow[t]{2}{*}{$0.001 *$} \\
\hline & Vaginal birth & 1076 & 28.2 & $260(24.2)$ & \\
\hline \multirow[t]{2}{*}{ Anaesthesia } & None & 137 & 3.6 & $37(27.0)$ & \multirow[t]{2}{*}{$0.001 *$} \\
\hline & Used & 3675 & 96.4 & 2187 (59.5) & \\
\hline General & & 422 & 11.1 & 311 (73.7\%) & $0.001 *$ \\
\hline Epidural & & 3253 & 85.3 & 1876 (57.7\%) & \\
\hline \multirow[t]{2}{*}{ Conception } & Spontaneous & 3501 & 91.8 & $2010(57.4)$ & \multirow[t]{2}{*}{$0.001 *$} \\
\hline & IVF & 311 & 9.2 & $214(68.8)$ & \\
\hline \multirow[t]{2}{*}{ Underlying Conditions } & None & 3249 & 85.2 & 1879 (57.8\%) & \multirow[t]{2}{*}{0.126} \\
\hline & Present & 563 & & 345 (61.3\%) & \\
\hline
\end{tabular}

Five risk factors were statistically significant after logistic regression analysis (Table 6). Caesarean section seems to be the most significant factor that increases risk of early weight loss by 7.92 times (Table 6). 
Table 6

Significant risk factors for higher than $7 \%$ weight loss

\begin{tabular}{|c|c|c|c|c|}
\hline & \multirow[t]{2}{*}{$p$} & \multirow[t]{2}{*}{ Odds Ratio } & \multicolumn{2}{|l|}{$\% 95 \mathrm{Cl}$} \\
\hline & & & Lower & Upper \\
\hline Maternal Age & 0,001 & & & \\
\hline \multicolumn{5}{|l|}{$<30 y r s$} \\
\hline $31-35$ yrs & 0,014 & 1,275 & 1,051 & 1,547 \\
\hline $36-40$ yrs & 0,001 & 1,665 & 1,335 & 2,076 \\
\hline$>40$ yrs & 0,002 & 1,780 & 1,226 & 2,584 \\
\hline Parity (primiparous) & 0,001 & 1,918 & 1,638 & 2,245 \\
\hline Gestational Week (37 and 38 wk) & 0,012 & 1,210 & 1,042 & 1,405 \\
\hline Mode of Delivery & 0,001 & 7,923 & 6,686 & 9,390 \\
\hline \multicolumn{5}{|l|}{ (Cesarean Section) } \\
\hline Gender (female) & 0.001 & 1,330 & 1,150 & 1,538 \\
\hline
\end{tabular}

Lower parity was also found statistically significant $(\mathrm{p}<0.01)$ for higher rates of birth weight loss. Weight loss over $7 \%$ for babies born to primiparous women was $61.2 \%$ and weight loss and number of births were inversely correlated; $54.2 \%$ for para $2,52.6 \%$ for para $3,42.9 \%$ for para 4 and $40 \%$ for para 5 women. The Odds of being born to a primiparous mother is 1,918 (\%95 Cl:1,638-2,245) (Table 6). Gestational week was also identified as a risk factor for early weight loss and early term babies had a higher risk of losing over $7 \%$ of their birth weight compared to those born 39 weeks and above. The Odds of being born as early term is 1,012 (\%95 Cl:1,21 - 1,042) (Table 6). Older maternal age was a significant risk factor for neonatal weight loss. The weight loss percentages were evaluated for four different groups as follows; younger than 30 years of age, between 31-35 years, between 36-40 years and above 40 years of age. Babies born to older mothers lost significantly more weight in comparison with the babies born to the younger mothers, for every group and for every measurement ( $p<0.01$ for all groups). Maternal age $>35$ years, increases the risk of early weight loss nearly 2 times (Table 6 ). Female gender was found to be significant after logistic regression analysis. The Odds of being a girl is 1,330 (\%95 Cl:1,150-1,538) (Table 6).

\section{Discussion}

In order to prevent early excessive weight loss in newborns identification of significant risk factors is crucial. If we identify significant risk factors, then we can figure out how and when to prevent early excess weight loss and hopefully also improve long term exclusive breastfeeding. These risk factors may change from country to country. To the best of our knowledge, this is the most extensive study in Turkey that has investigated risk factors for early weight loss in breastfed and term newborns. cesarean section (CS), primiparity, gestational age, maternal age and female gender were the significant risk factors found in the study.

WHO has stated that no robust evidence existed for ideal CS rate. The rate in our study was quite high (15). In Turkey CS rates has increased five folds during the period of 1993-2013 (16). The latest CS rate of 2018 was 52\% (17). In literature, there were studies that had smaller number of cases to identify CS delivery as a barrier for breastfeeding $(18,19)$. Due to the size of this study group and high ratio of CS, the results obtained in this study are clear of the effects of other risk factors. Late skin to skin, post-operative pain and IV fluid administration may be associated with lower success rates in exclusive breastfeeding following CS $(20,21)$.

According to our findings neonatal weight loss rate was statistically significant for maternal age above 35 years. This is parallel with previous findings from various studies $(19,22)$. However, many research analyses the combined effect of maternal age and parity $(23,24)$. Due to our study's large data, it was possible to identify maternal age as an independent risk factor from parity. Delayed childbearing can be a barrier for breastfeeding and galactagogue use can be an alternative method of lactation support (25).

Being primiparous was another prominent risk factor of our study. This finding is especially valuable as it has been eminent in a study where maternal age was also evaluated. The rate of weight loss $>7 \%$ was $61.2 \%$ among babies born as the first child of the family. This may be related maternal inexperience and anxiety $(4,23)$. Such anxieties may have detrimental effect on successful breastfeeding $(26)$. Multiparas show earlier start of breastfeeding which may be associated with previous experience (27).

In our study, over $64 \%$ of the early term babies (37 weeks 0 days- 38 weeks and 6 days) lost more than $7 \%$ of their birth weight whereas the percentage of excessive weight loss for term babies were around 51\% (Tables 4 and 5). This notable difference may be due to increased 
mortality and hospital stay, difficulty in regulating blood glucose, increased respiratory morbidities and newborn intensive care admissions (28, 29). The sleepiness and reduced ability to effectively latch on is a major problem of early term babies. Even if some early term infants may seem to latch on properly, they may not be able to transfer adequate amount of breastmilk. They require additional attention as breastfeeding support (10).

Findings about gender as a risk factor for early weight loss is controversial. In one study where risk factors for early lactation problems among primiparous mothers were investigated, being boy was observed as a risk factor. The reasons of this finding were explained as; sex-specific differences in infant suckling maturation, gender-based differential behaviours in mothers or the observed association may be because of chance (30). In another study, where 414 newborns were evaluated for the risk factors over $8 \%$ weight loss, gender difference was not found to be significant (19). In our study, being a girl was a risk for early weight loss. According to WHO, child growth velocity based on weight, for the first 7 days of life boys' weight increment was found $21 \mathrm{gr} /$ day whereas girls had $14 \mathrm{gr} /$ day average regardless of birth weight (31). Obviously, there are physiological differences between genders in terms of early weight loss and gain. Further prospective studies that investigate the effect of gender on infant weight loss after birth are needed.

The study has some limitations. Information on the management of maternal gestational diabetes mellitus, maternal increased insulin resistance and maternal hypothyroidism was not gathered. The study group consisted majorly of women who were administered anaesthesia, general or epidural. This may have limited the expression of the group of mothers that received no anaesthesia. Birth weight of newborns were mostly above 3000 grams.

\section{Conclusion}

Older maternal age and being primiparous are the identified risk factors determined during pregnancy for early weight loss. Suggested interventions to identified risks were given at Table 7. Perinatal courses may inform mothers about how they can overcome breastfeeding problems. Attentive breastfeeding support immediately after delivery for those women may decrease early weight loss. Perinatal courses promoting natural birth may prove to be useful (32). By helping mother making informed decisions about mode of delivery and use of anaesthesia is beneficial on many levels: awake mothers who do not miss out the 'Golden Hour' and babies with lower anaesthetics in their bloodstream (33). Assisted breastfeeding techniques (Table 1) can be used and close follow-up for early term babies will likely ensure prolonged successful exclusive breastfeeding period (10). 


\begin{tabular}{|c|c|c|c|}
\hline \multirow[t]{2}{*}{ Risks } & \multicolumn{3}{|l|}{ Suggested Interventions } \\
\hline & Prenatal & Perinatal & Postnatal \\
\hline CS & Perinatal courses & $\begin{array}{l}\text { Perioperative sensible IV fluid } \\
\text { administration }\end{array}$ & $\begin{array}{l}\text { - Early skin-to skin contact, } \\
\text { - Repeated lactation } \\
\text { consultancy } \\
\text { - Postoperative pain } \\
\text { management }\end{array}$ \\
\hline Primipar & Perinatal courses & Encouraging normal birth & $\begin{array}{l}\text { - Postpartum anxiety } \\
\text { management } \\
\text { - Lactation consultancy }\end{array}$ \\
\hline $\begin{array}{l}\text { Advanced } \\
\text { maternal age }\end{array}$ & Perinatal courses & Encouraging normal birth & $\begin{array}{l}\text { Closer breastfeeding } \\
\text { follow-up } \\
\text { - Galactagogue use? }\end{array}$ \\
\hline Gestational age & $\begin{array}{l}\text { Perinatal courses } \\
\text { - Managing sleepy baby } \\
\text { - Explaning physiology of lactation (stimulus } \\
\text { leads to production) }\end{array}$ & Encouraging normal birth & $\begin{array}{l}\text { Closer breastfeeding } \\
\text { follow-up } \\
\text { - Assisted breastfeeding } \\
\text { techniques } \\
\text { - Hand expression } \\
\text { - Cup feeding } \\
\text { - Possible mechanical } \\
\text { expression }\end{array}$ \\
\hline Gender & Routine follow-up & Routine follow-up & $\begin{array}{l}\text { Closer breastfeeding } \\
\text { follow-up }\end{array}$ \\
\hline
\end{tabular}

\section{Abbreviations}

WHO

The World Health Organisation

UNICEF

United Nations International Children's Fund

MOM

Mother's own milk

IVF

In vitro fertilisation

GDM

Gestational diabetes mellitus

TSH

Thyroid-stimulating hormone

CS

Caesarean section

\section{Declarations}

- Ethics approval: This study had Koc University ethics committee approval (19.03.2015/ 2015.058.IRB2.024).

- Consent for publication: None applicable

- Availability of data and materials: The datasets used and/or analyzed during the current study are available from the corresponding author upon reasonable request.

- Competing interests: The authors declare that no competing interests exist

- Funding: The authors received no financial support for the research, authorship, and/or publication of this article.

- Authors' contributions: Author have made substantial contributions; 
TE: Design of the work, analysis, interpretation of data, drafted the work.

BK: Design of the work, analysis, interpretation of data, drafted the work.

GG: Design of the work, analysis, interpretation of data, drafted the work

- Acknowledgements: This study was presented as poster (poster no: 45) at Academy of Breastfeeding Medicine $24^{\text {th }}$ Annual International Meeting, Blackburn, UK, October 16-19,2019.

\section{References}

1. UNICEF/WHO. (2009). Baby-Friendly Hospital Initiative: Revised, Updated and Expanded for Integrated Care, Sect. 1, Background and Implementation, Preliminary version.

https://apps.who.int/iris/bitstream/handle/10665/43593/9789241594967_eng.pdf;jsessionid=62D44EC8221A7324A9488561160A2B17? sequence $=1$ (Last Accessed date:22.02.2020).

2. Dewey KG. Nommsen-Rivers LA, Heinig MJ, Cohen RJ. Risk Factors for suboptimal infant breastfeeding behavior, delayed onset of lactation and excess neonatal weight loss. Pediatrics. 2003;112(3):607-19. DOI:10.1542/peds.112.3.607.

3. Johnston M, Landers S, Noble L, Szucs K, Viehmann L. Section on Breastfeeding. Breastfeeding and the use of human milk. Pediatrics. 2012;129(3):e827-41.

4. Lewallen LP, Dick MJ, Flowers J, Powell W, Zickefoose KT, Wall YG, et al. Breastfeeding support and early cessation. J Obstet Gynecol Neonatal Nurs. 2006;35(2):166-72. DOI:10.1111/j.1552-6909.2006.00031.x.

5. Chen YJ, Chen WC, Chen CM. Risk factors for hyperbilirubinemia in breastfed term neonates. Eur J Pediatr. 2012;171(1):167-71. DOI:10.1007/s00431-011-1512-8.

6. Livingstone VH, Willis CE, Abdel-Wareth LO, Thiessen P, Lockitch G. Neonatal hypernatremic dehydration associated with breast-feeding malnutrition: a retrospective survey. CMAJ. 2000;162:647-52. PMID: 10738450; PMCID: PMC1231219.

7. Holmes AV, Auinger P, Howard CR. Combination feeding of breast milk and formula: Evidence for shorter breast-feeding duration from the National Health and Nutrition Examination Survey. J Pediatr. 2011;159(2):186-91. DOI:10.1016/j.jpeds.2011.02.006.

8. Thulier D Challenging Expected Patterns of Weight Loss in Full-Term Breastfeeding Neonates Born by Cesarean. J Obstet Gynecol Neonatal Nurs 2017;46(1):18-28. DOI:10.1016/j.jogn.2016.11.006.

9. Michel MP, Gremmo-Feger G, Oger E, Sizun J. Pilot study of early breastfeeding difficulties of term newborns:incidence and risk factors. Arch Pediatr. 2007;14(5):454-60. DOI:10.1016/j.arcped.2007.01.005.

10. Boies E, Vaucher YE. the Academy of Breastfeeding Medicine. ABM Clinical Protocol \#10: Breastfeeding the late preterm (34-36 6/7 weeks of gestation) and early term infants (37-38 6/7 weeks of gestation) Second Revision 2016. Breastfeed Med 2016, 11(10), 494-500. DOI:10.1089/bfm.2016.29031.egb.

11. Hamilcikan Ş, Gok V, Bent S, Can E. Early Weight Loss in Exclusively Breastfed Term Neonates. Iran J Pediatr. $2017 ; 27(2):$ e9497. DOI:10.5812/ijp.9497.

12. Çaglar MK, Özer I, Altugan FS. Risk factors for excess weight loss and hypernatremia in exclusively breast-fed infants. Braz J Med Biol Res 2006; 39(4):539-44. DOI:10.1590/s0100-879x2006000400015.

13. The American College of Obstetricians and Gynecologists Committee on Practice Bulletins-Obstetrics. Practice Bulletin No. 180: Gestational Diabetes Mellitus. Obstet Gynecol.. 2017;130(1):e17-e37DOI: 10.1097/AOG.0000000000002159.

14. Idris I, Srinivasan R, Simm A, Page RC. Maternal hypothyroidism in early and late gestation: effects on neonatal and obstetric outcome. Clin Endocrinol (Oxf). 2005;63(5):560-5. DOI:10.1111/j.1365-2265.2005.02382.x.

15. Vogel JP, Betrán AP, Vindevoghel N, Souza JP, Torloni MR, Zhang J, et al. Use of the Robson classification to assess caesarean section trends in 21 countries: a secondary analysis of two WHO multicountry surveys. Lancet Glob Health. 2015;3(5):e260-70. DOI:10.1016/S2214-109X(15)70094-X.

16. Santas G, Santas F. Trends of caesarean section rates in Turkey. J Obstet Gynaecol. 2018;38(5):658-62.

17. Hacettepe University Institute of Population Studies. "2018 Turkey Demographic and Health Survey". Turkey: Hacettepe University Institute of Population Studies, T.R. Ministry of Development and TÜBiTAK, Ankara; 2019.

18. Fisher J, Hammarberg K, Wynter K, McBain J, Gibson F, Boivin J. et. al. Assisted conception, maternal age and breastfeeding: an Australian cohort study. Acta Paediatr. 2013;102(10):970-6. DOI:10.1111/apa.12336.

19. Mezzacappa MA, Ferreira BG. Excessive weight loss in exclusively breasted full-term newborns in a baby-friendly hospital. Rev Paul Pediatr 2016; 34:281-6. DOI:10.1016/j.rpped.2015.10.007.

Page 9/10 
20. Flaherman VJ, Aby J, Burgos AE, Lee KA, Cabana MD, Newman TB. Effect of early limited formula on duration and exclusivity of breastfeeding in at-risk infants: an RCT. Pediatrics. 2013;131(6):1059-65. DOI:10.1542/peds.2012-2809.

21. Flaherman VJ, Kuzniewicz M, Li S, Walsh E, McCulloch CE, Newman TB. First-day weight loss predicts eventual weight nadir for breastfeeding newborns. Arch Dis Child Fetal Neonatal Ed. 2013;98:F488-92. DOI:10.1136/archdischild-2012-303076.

22. Fonseca MJ, Severo M, Barros H, Santos A. Determinants of weight changes during the first 96 hours of life in full-term newborns. Birth 2014;41(2):160-8. DOI: 10.1111/birt.12087.

23. Dennis CL, Coghlan M, Vigod S. Can we identify mothers at-risk for postpartum anxiety in the immediate postpartum period using the State-Trait Anxiety Inventory? J Affect Disord 2013; 150:1217-20. DOI:10.1016/j.jad.2013.05.049.

24. Kitano N, Nomura K, Kido M, Murakami K, Ohkubo T, Ueno M.et al. Combined effects of maternal age and parity on successful initiation of exclusive breastfeeding. Preventive Medicine Reports 2016; 3:121-6. DOI:10.1016/j.pmedr.2015.12.010.

25. Bazzano AN, Cenac L, Brandt AJ, Barnett J, Thibeau S, Theall KP. Maternal experiences with and sources of information on galactagogues to support lactation: a cross-sectional study. Int J Womens Health. 2017;9:105-13. DOI:10.2147/IJWH.S128517.

26. Kronborg H, Harder I, Hall EO. First time mothers' experiences of breastfeeding their newborn. Sexual Reproductive Healthcare 2015;6:827. DOI:10.1016/j.srhc.2014.08.004.

27. Ekström A, Widström AM, Nissen E. Duration of breastfeeding in Swedish primiparous and multiparous women. J Hum Lact. 2003;19:1728. DOI:10.1177/0890334403252537.

28. Huang K, Yan S, Wu X, Zhu P, Tao F. Elective caesarean section on maternal request prior to 39 gestational weeks and childhood psychopathology: a birth cohort study in China. BMC Psychiatry. 2019;19(1):22. DOI:10.1186/s12888-019-2012-z.

29. Adamkin DH. Committee on Fetus and Newborn. Clinical Report- Postnatal Glucose Homeostasis in Late-Preterm and Term Infants. Pediatrics 2011; 217(3):575-9. DOI:10.1542/peds.2010-3851.

30. Matias SL, Nommsen-Rivers LA, Creed-Kanashiro H, Dewey KG. Risk factors for early lactation problems among Peruvian primiparous mothers. Matern Child Nutr. 2010;6(2):120-33. DOI:10.1111/j.1740-8709.2009.00195.x.

31. World Health Organization. (2009). WHO child growth standards: growth velocity based on weight, length and head circumference: methods and development. World Health Organization. https://apps.who.int/iris/handle/10665/44026.

32. Holmes AV. Establishing successful breastfeeding in the newborn period. Pediatr Clin North Am. 2013;60:147-68. DOI:10.1016/j.pcl.2012.09.013.

33. Phillips R. The sacred hour: Uninterrupted skin-to-skin contact immediately after birth. Newborn Infant Nursing Reviews. $2013 ; 13(2): 67-72$. DOI:10.1053/j.nainr.2013.04.001.

\section{Figures}

From 1 January 2011 to 31 December 2014, 4221 newborn delivered

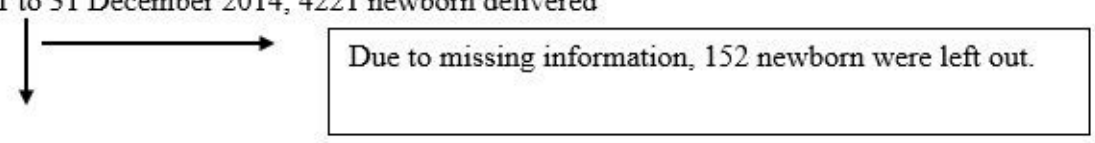

For the study 4069 newborns' records were elligable

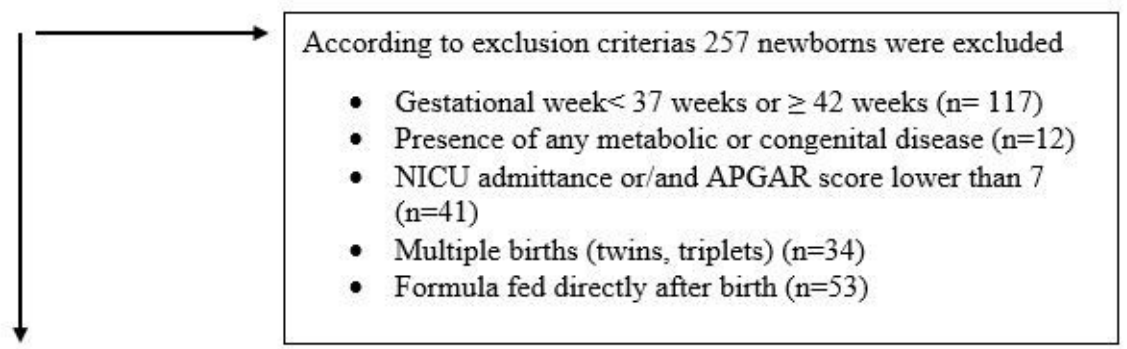

Total of 3812 newborns have been included in the study

\section{Figure 1}

Flowchart of the study 